\title{
Right Device Assessment and Selection in Pediatrics
}

\author{
Tricia Kleidon and Amanda Ullman
}

\begin{abstract}
Achieving vascular access in infants and pediatrics can be physically and emotionally challenging; therefore, every attempt to mitigate unnecessary venous access should be considered. The Infusion Nursing Standards of Practice recommends that, after assessment of all pertinent factors, the least invasive device to facilitate the prescribed treatment for the required time be inserted.
\end{abstract}

\section{Keywords}

Pediatric device selection - Device assessment $\cdot$ Intravenous $\cdot$ Catheter
T. Kleidon $(\bowtie)$

Queensland Children's Hospital and Alliance for Vascular Access Teaching and Research (AVATAR), Brisbane, QLD, Australia

e-mail: tricia.kleidon@health.qld.gov.au

A. Ullman

Alliance for Vascular Access Teaching and Research (AVATAR) Group, Menzies Health Institute Queensland, School of Nursing and Midwifery, Griffith University, Brisbane, QLD, Australia e-mail: a.ullman@griffith.edu.au

\subsection{Introduction}

Interdisciplinary discussion should precede any vascular access decision to ensure the right device is inserted for the pediatric patient at the right time to enable the necessary treatment. Vascular access devices (VADs) should only be used when necessary, and other treatment options such as oral antibiotics, intranasal analgesia, and enteral fluid therapy should be considered when appropriate. If a VAD is necessary, choice is based on the indication, duration, and frequency of treatment, the properties of the infusate, and, when possible, the preference of the patient or caregiver. Chopra et al. (2015) recently published the Michigan Appropriateness Guide for Intravenous Catheters (MAGIC) to develop appropriateness criteria for VAD selection, care, and management (Chopra et al. 2015). While the algorithms contained within this study were based on the needs of adult patients, the study emphasizes the usefulness and necessity of a device selection algorithm to guide VAD choice. While selection of the right vascular access device is not always obvious, and many device decisions will fall outside the bounds of the most comprehensive algorithm, an algorithm should be used as a guide to generate interdisciplinary discussion regarding the right device choice for the patient. Figure 14.1 illustrates a pediatric VAD decision-making algorithm which has been used successfully in tertiary pediatric facilities to guide this complex decision-making. 
Please see Vascular Access Device (VAD) Decision Tree below. The VAD Decision Tree is a guide to the most appropriate device for your patient and should guide device selection when VAMS NP is not available.

\section{Central Venous Access Devices (CVAD) in Children}

The following VAD Decision Tree should be used as a guide only and all other CVAD enquiries directed to VAMS NP

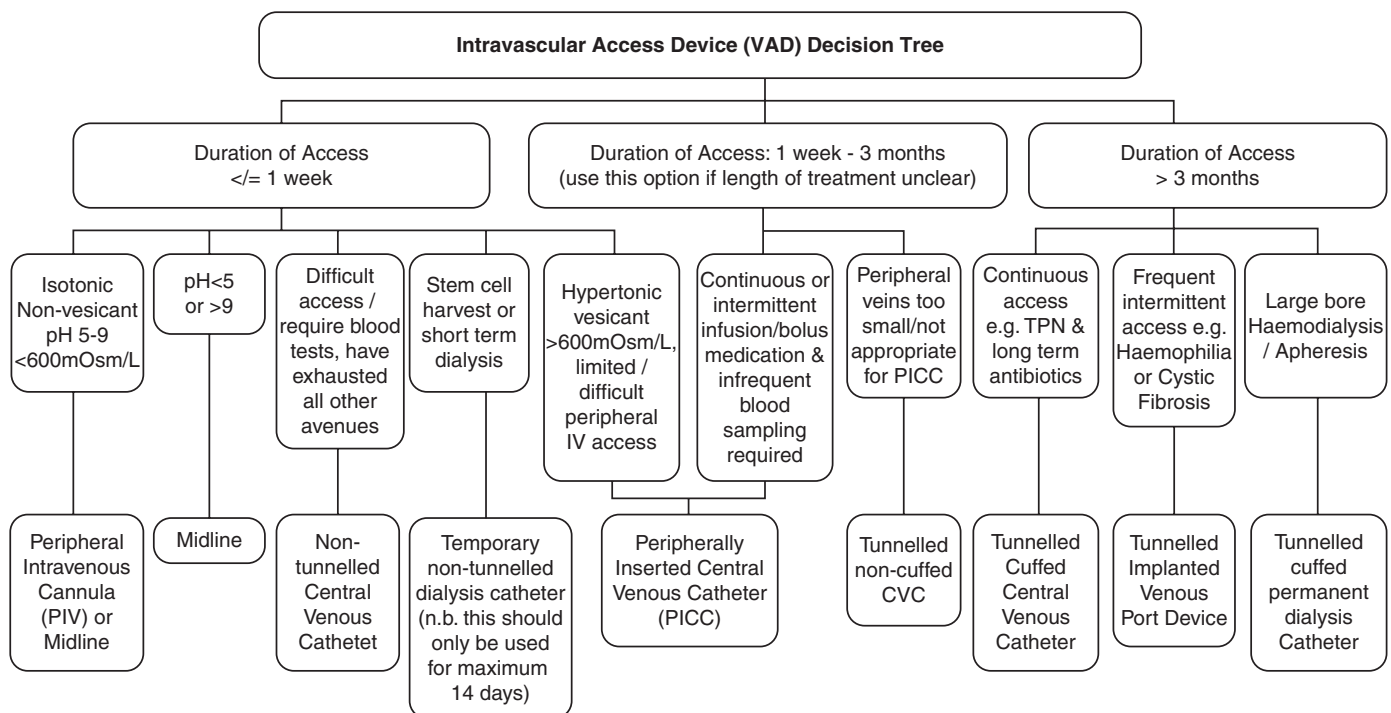

Decision for venous access device should be made using the Decision Tree as a guide only. For complex cases, especially neonatal lines, device selection should be made in conjuction with all clinical teams involved in care, including VAMS NP when available.

When choosing the most appropriate device the following principles must be adhered to:

1. Right device inserted first time

2. Smallest possible device for completion of treatment

3. Minimum number of lumens required for completion of treatment

Fig. 14.1 VAD decision-making algorithm (used with permission from Children's Health Services (2016))

\subsection{Device Options}

\subsubsection{Peripheral Intravenous Cannula (PIVC)}

A peripheral intravenous cannula (PIVC) is the most commonly used VAD in hospitalized patients and is primarily used for the infusion of fluid and fluid resuscitation, administration of antibiotics, some chemotherapy, and the administration of other parenteral medications (Alexandrou et al. 2015; Marsh et al. 2015; Kleidon et al. 2019). It is estimated that approximately $47 \%$ of hospitalized pediatric patients have a PIVC (Ullman et al. 2016). Placement of a PIVC in infants and young children is time-consuming and difficult due to smaller, less visible, or palpable veins, reduced procedural cooperation, increased adipose tissue, vasoconstriction, and parental anxiety (Malyon et al. 2014; Kleidon et al. 2019). Pediatric inpatients report PIVC insertions as the leading source of procedure-related pain while in hospital (Zempsky 2008). For these reasons, it is important to ensure that the PIVC is the most appropriate device to facilitate the necessary treatment.

\section{Criteria for Appropriate PIVC Use}

- Short term.

- Inserted into small peripheral vessels of the upper and lower limbs.

- Scalp veins have been used previously in infants and neonates; however, with the availability and use of technology to assist peripheral vein identification and PIVC insertions, 
fewer scalp vein insertions are necessary (Benkhadra et al. 2012; Juric and Zalik 2014) (see Chap. 15).

- Suitable for a variety of nonirritant infusion therapies.

- Minimally invasive.

- Almost all doctors and nurses are skilled in this procedure.

PIVCs range from 24 gauge (which is the smallest and most commonly used in neonates and infants) to 14 gauge, which is infrequently used in pediatric patients but may be required in various situations including trauma, fluid resuscitation, or blood transfusion in adolescents as they accommodate greater flow and limit hemolysis (Gorski et al. 2016; L'Acqua and Hod 2015). Table 14.1 further describes the characteristics and indications of PIVC gauges in pediatrics.

PIVCs are short devices, ranging from 2 to $6 \mathrm{~cm}$ in length. New, longer PIVCs are available in 20 gauge or greater, with some countries (e.g., the United States) also having a longer 22-gauge PIVC available. The benefit of these longer devices is the ability to access veins that are deep to the skin surface while still ensuring enough cannula is anchored in the vessel to reduce the risk of dislodgement. This is commonly referred to as "vessel purchase." Ideally half of the PIVC will be situated within the actual vessel itself, while the remainder is within the subcutaneous layer (Pandurangadu et al. 2018). See Fig. 14.2-looking down the right-hand side of the ultrasound image, you will note numeric markings indicating depth in centimeters. The red arrow indicates the vessel to be punctured is $1 \mathrm{~cm}$ deep. Due to the size of this vessel, direct puncture is required to ensure half of the PIVC is within the vessel, reducing the risk of dislodgement.

Table 14.1 PIVC size and use

\begin{tabular}{|c|c|c|}
\hline $\begin{array}{l}\text { Gauge and } \\
\text { length }\end{array}$ & Usual age & Purpose \\
\hline $24 \mathrm{G}$ & $\begin{array}{l}\text { Neonates } \\
\text { Infants }\end{array}$ & $\begin{array}{l}\text { Most infusions } \\
\text { Day infusion } \\
\text { Small superficial } \\
\text { vessel }\end{array}$ \\
\hline 22 g (short) & $\begin{array}{l}\text { Toddlers and } \\
\text { school age }\end{array}$ & $\begin{array}{l}\text { Most infusions } \\
\text { Minimal adiposity }\end{array}$ \\
\hline 22 g (long) & $\begin{array}{l}\text { Toddlers and } \\
\text { school age }\end{array}$ & $\begin{array}{l}\text { Ultrasound-guided } \\
\text { insertion } \\
\text { Excessive adipose } \\
\text { tissue }\end{array}$ \\
\hline $20 \mathrm{~g}$ (short) & $\begin{array}{l}\text { School age } \\
\text { Older school age } \\
\text { and adolescence }\end{array}$ & $\begin{array}{l}\text { Intraoperative } \\
\text { Trauma, fluid } \\
\text { resuscitation } \\
\text { Blood sampling } \\
\text { on insertion } \\
\text { Most infusions } \\
\text { Minimal adiposity }\end{array}$ \\
\hline 20 g (long) & $\begin{array}{l}\text { Older school age } \\
\text { and adolescence }\end{array}$ & $\begin{array}{l}\text { Ultrasound-guided } \\
\text { insertion } \\
\text { Excessive adipose } \\
\text { tissue }\end{array}$ \\
\hline $\begin{array}{l}>20 \mathrm{~g} \text { and } \\
\text { up to } 14 \mathrm{~g}\end{array}$ & $\begin{array}{l}\text { Older school age } \\
\text { and adolescence }\end{array}$ & $\begin{array}{l}\text { Intraoperative } \\
\text { Trauma, fluid } \\
\text { resuscitation } \\
\text { Blood sampling } \\
\text { on insertion } \\
\text { Most infusions }\end{array}$ \\
\hline
\end{tabular}

Fig. 14.2 Ultrasound imaging showing vessel depth (used with permission T. Kleidon)

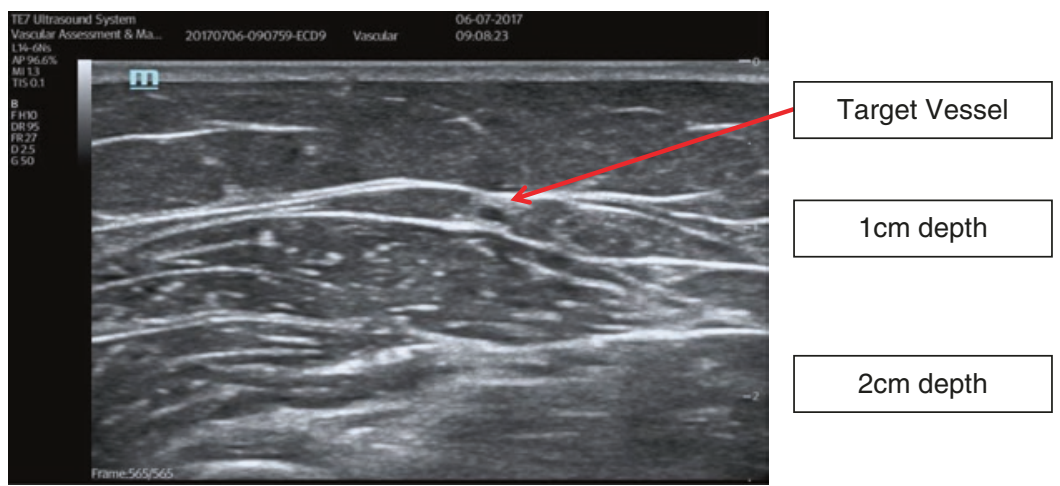




\section{Inappropriate use of PIVC includes:}

- Infsuion of vesicants or other irritants, which should be infused through a central venous access device will be discussed later in this chapter. Inadvertent administration of irritants or vesicants into a peripheral vein can result in tissue-damaging necrosis requiring surgical intervention to treat (see Figs. 14.3 and 14.4).

- Routine blood sampling, other than initial insertion bloods.

- Just in case-the continued need for PIVC should be reviewed daily. If the PIVC is no longer necessary, it should be removed (Kleidon et al. 2019).

\section{PIVCs should be reviewed daily to assess:}

- Function: Does the PIVC still infuse; is there any leakage evident at the site?

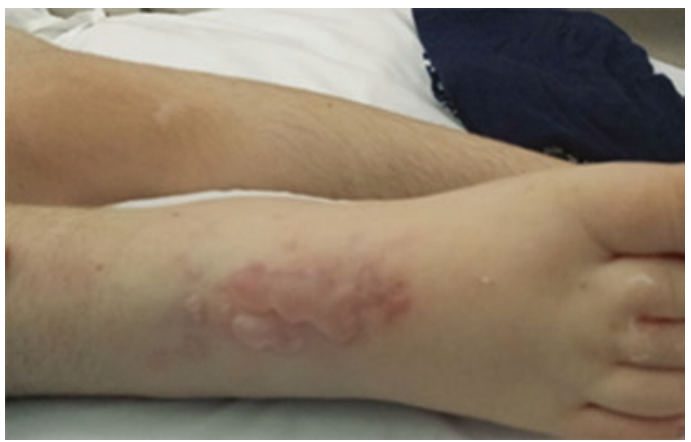

Fig. 14.3 Extravasation (used with permission T. Kleidon)

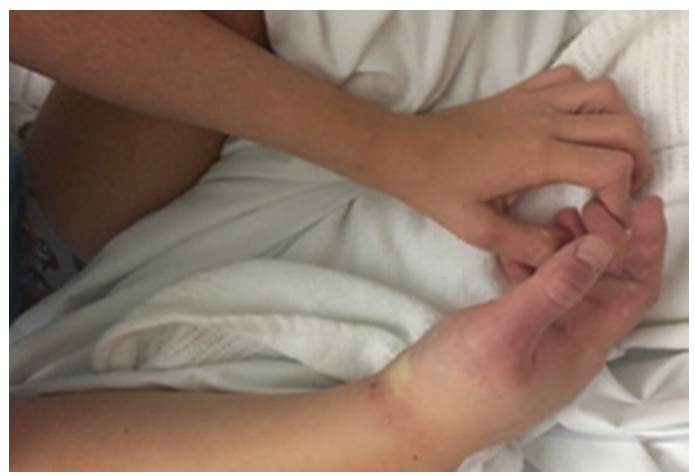

Fig. 14.4 Infiltration (used with permission T. Kleidon)
- Complication: Any signs of local complication such as infiltration, extravasation, phlebitis, or dislodgement (see Figs. 14.5 and 14.6).

- Necessity: Is the PIVC still clinically indicated?

If any of these criteria are met, the PIVC must be removed and replaced, if necessary. Most pediatric hospitals have never routinely replaced PIVCs at regular 72-96-h intervals. High-quality research has confirmed this as best practice. Clinicians should replace pediatric PIVCs when clinically indicated rather than at routine intervals; this practice does not lead to an increased risk of complications (Rickard et al. 2012; Webster et al. 2015). Pediatric nurses are now tasked with exploring insertion-related factors that may prolong the functional duration of PIVCs including the use of ultrasound for insertion and placement of PIVCs in the forearm rather than those of the hand, wrist, or feet.

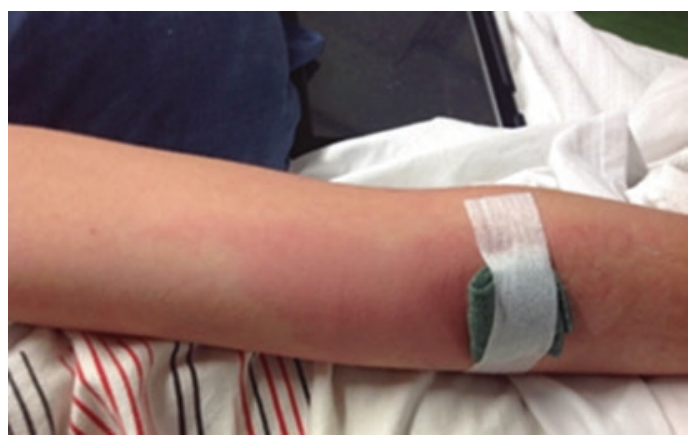

Fig. 14.5 Phlebitis (used with permission T. Kleidon)

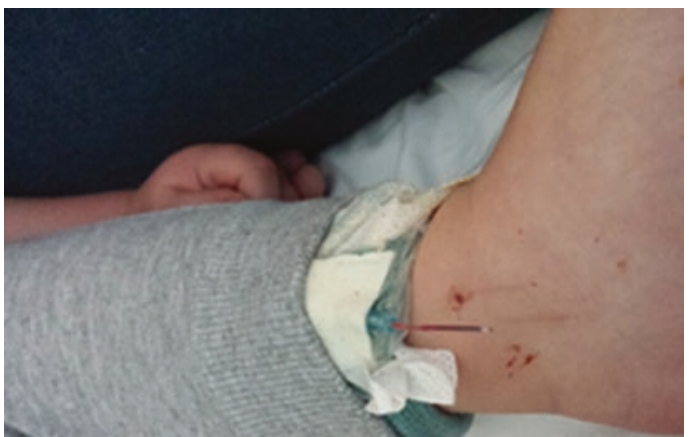

Fig. 14.6 Dislodgement. Dressing no longer clean, dry, or intact (used with permission T. Kleidon) 


\subsubsection{Midlines}

A midline (see Fig. 14.7) is an alternative to a PIVC and should be considered when intravenous medications such as antibiotics are prescribed for a period of time greater than the average dwell time of a PIVC in your institution. The tip of a midline typically sits in the basilic, brachial, or cephalic veins at or below the axillary fold, distal to the shoulder (Gorski et al. 2016). The comparative properties of PIVC, midlines, and PICCs are displayed in Table 14.2.

Midlines come in a variety of sizes and are not yet uniform. Some midlines are sized by gauge $(\mathrm{G})$, while others have been converted to French (Fr).

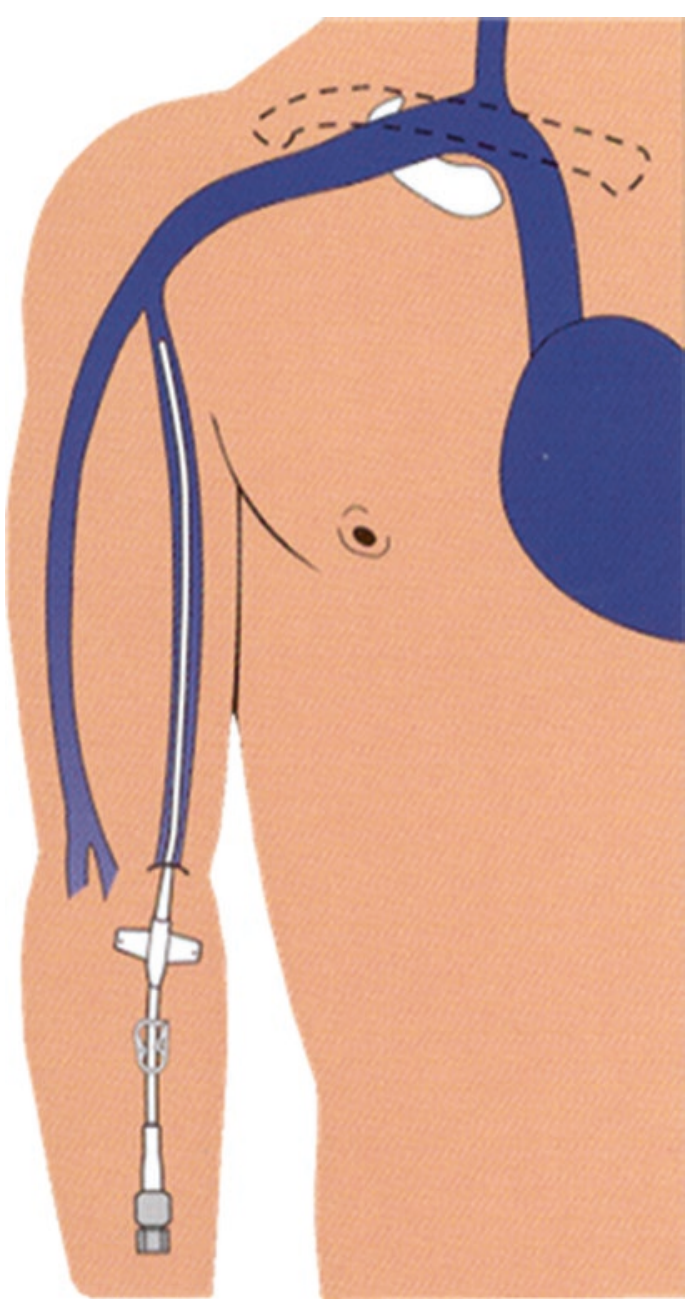

Fig. 14.7 Placement of a midline catheter (used with permission N. Moureau, PICC Excellence)
There is limited choice in some countries, and availability depends on the relevant regulatory approvals in your country such as US Food and Drug Approval (FDA), European "Conformité Européenne" (CE marking), or the Australian Therapeutic Goods Administration (TGA). To minimize the risk of thrombosis, most pediatric patients will be best suited to a $22-20$ G or 3-4Fr catheter. Catheter to vein ratio will be discussed in the PICC section of this chapter but should also be considered when selecting an appropriately sized midline.

\section{Criteria for Appropriate Midline Use}

Overall, limited evidence regarding the efficacy of midlines is available. However, general indications include:

- Extended dwell peripheral intravenous therapy-longer dwell times than standard PIVCs (see Table 14.2) (Gorski et al. 2016).

- Intravenous infusions of 1-4 weeks duration.

- The increased length of a midline compared to a PIVC might reduce the risk of dislodgement. Additionally, the larger diameter of the vein where the midline terminates reduces the risk of phlebitis and occlusion compared to the smaller vein locations of PIVCs (Caparas and Hu 2014; Tagalakis et al. 2002).

- Avoid infusions with irritating properties. Consider $\mathrm{pH}$ and characteristics of medication (Caparas and Hu 2014; Gorski et al. 2015).

- Short durations ( $<6$ days) of diluted medications such as vancomycin, which typically has a $\mathrm{pH}$ of 4 , may be infused through a midline that has its tip terminating in a larger, proximal upper arm vessel (Caparas and $\mathrm{Hu} 2014$ ).

- Midlines are not indicated for continuous vesicant therapy, parenteral nutrition where dextrose is $>10 \%$ and protein $>5 \%$, or infusates with an osmolarity greater than $900 \mathrm{mOsm} / \mathrm{L}$ (Gorski et al. 2016; Royal College of Nursing 2016).

- Administration of intermittent vesicant medication through a midline should be performed with extreme caution due to the risk of undetected extravasation. 
Table 14.2 Properties of PIVC, midline, and PICC

\begin{tabular}{|c|c|c|c|}
\hline Property & PIVC & Midline & PICC \\
\hline Size & 24G-14G & $\begin{array}{l}3 \mathrm{Fr} \text { or } 4 \mathrm{Fr} \\
22 \mathrm{G} \text { or } 20 \mathrm{G}\end{array}$ & $\begin{array}{l}\text { 1Fr, 2Fr, 3Fr, 4Fr, 5Fr (single } \\
\text { lumen) } \\
\text { 2Fr (neonates), 4Fr, 5Fr } \\
\text { 6Fr (triple lumen) }\end{array}$ \\
\hline Length & $\begin{array}{l}\text { Variable, usually } \\
2-6 \mathrm{~cm}\end{array}$ & $4-12 \mathrm{~cm}$ (may be longer in adults) & $\begin{array}{l}55-60 \mathrm{~cm} \\
\text { Can be trimmed to } \\
\text { appropriate length }\end{array}$ \\
\hline $\begin{array}{l}\text { Insertion } \\
\text { position }\end{array}$ & $\begin{array}{l}\text { Peripheral vessel of } \\
\text { upper or lower limb }\end{array}$ & $\begin{array}{l}\text { Upper arm } \\
\text { Basilic, brachial, cephalic }\end{array}$ & $\begin{array}{l}\text { Upper arm } \\
\text { Basilic, brachial, cephalic }\end{array}$ \\
\hline Tip position & Peripheral & Distal to axillar & $\begin{array}{l}\text { SVC/RA junction (upper arm } \\
\text { insertion) } \\
\text { IVC (lower limb insertion) }\end{array}$ \\
\hline $\begin{array}{l}\text { Tip } \\
\text { confirmation }\end{array}$ & Not necessary & $\begin{array}{l}\text { No imaging necessary use measurement } \\
\text { to ensure correct tip positioning }\end{array}$ & $\begin{array}{l}\text { Tip confirmation with X-ray } \\
\text { or ECG }\end{array}$ \\
\hline $\begin{array}{l}\text { Flow rates } \\
\text { around tip }\end{array}$ & $20-40 \mathrm{~mL} / \mathrm{min}$ & $100-150 \mathrm{~mL} / \mathrm{min}$ & $2 \mathrm{~L} / \mathrm{min}$ \\
\hline $\begin{array}{l}\text { Clinical } \\
\text { indication }\end{array}$ & $\begin{array}{l}\text { Day infusion } \\
\text { Short-term therapy, } \\
\text { usually } 2-5 \text { days }\end{array}$ & $\begin{array}{l}\text { Infusion greater than } 5 \text { days } \\
\text { Medication/infusions up to } 2 \text { weeks } \\
\text { (may be indicated up to } 4 \text { weeks) } \\
\text { Dilute infusions when } \mathrm{pH}<5 />9 \\
\text { Modified parenteral nutrition, i.e., } \\
</=10 \% \text { Dextrose, protein } 5 \%\end{array}$ & $\begin{array}{l}\text { Vesicants } \\
\text { Continuous chemotherapy } \\
\text { Parenteral nutrition } \\
\text { Long-term treatment } \\
>2 \text { weeks }\end{array}$ \\
\hline
\end{tabular}
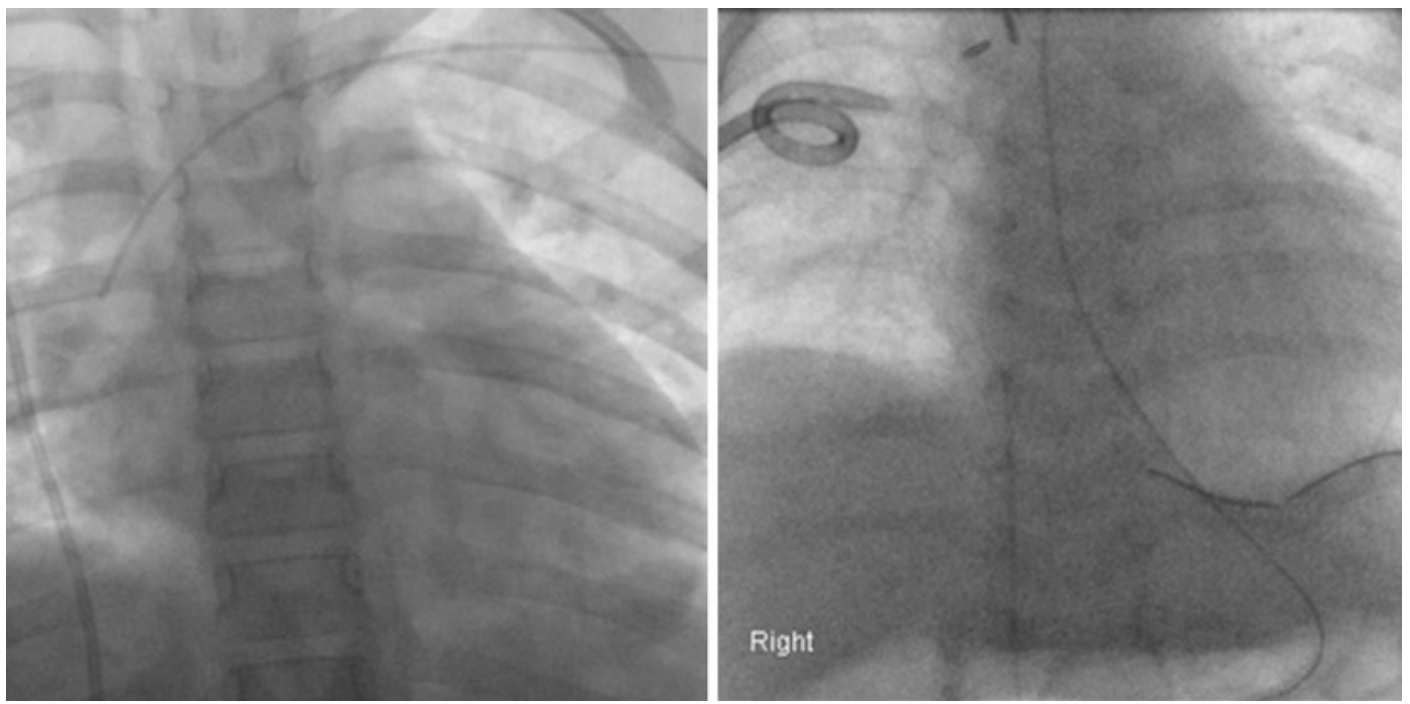

Fig. 14.8 PICC terminal tip placement (SVC and IVC) (used with permission T. Kleidon)

\subsubsection{Peripherally Inserted Central Catheters (PICCs)}

A peripherally inserted central catheter (PICC) is a long catheter that is approximately $55-60 \mathrm{~cm}$ untrimmed, with most trimmable to a more appropriate length for pediatric patients. PICCs are inserted into peripheral veins of the upper arm (basilic, brachial, or cephalic) and lower limbs (greater saphenous) in pediatrics. The tip of the catheter is advanced to a central position, either the cavoatrial junction (junction of the superior vena cava and right atrium) if upper limb PICC insertion (image on the left) or inferior vena cava if inserted from the lower limbs (Fig. 14.8). Because the tip of a PICC terminates 
in a central vessel, the blood flow around the catheter is high, usually $2 \mathrm{~L}$ or more per minute. This provides immediate dilution of the infusate and helps protect the vessel walls from chemical irritation from the prescribed intravenous medication.

\section{Criteria for Appropriate PICC Use}

- Central venous access for patients in acute care and home care or outpatient facilities.

- Extended venous access dwell is necessary and may remain in situ for weeks, months, and sometimes years (Hatakeyama et al. 2011).

- Reliable alternative to short-term central venous catheters with presumably fewer complications.

- If multiple infusions including those only suitable for central infusion are required, insertion of a PICC has less complication compared to a catheter that has its origin in a neck vessel. For example, complications such as pneumothorax, hemothorax, and uncontrolled bleeding are comparatively less likely to occur during PICC insertions (Hatakeyama et al. 2011; Westergaard et al. 2013).

- While PICCs have a lower complication profile, they're not innocuous, and experienced clinicians suggest vascular access professionals should adopt a more considered approach to the situations that are suitable for PICC insertion (Chopra et al. 2015).

PICCs range in size from $3 \mathrm{Fr}$ to $6 \mathrm{Fr}$ and are single- or multi-lumen devices. Just as the decision to insert the right device should be made collaboratively, so should the decision regarding the number of lumens that are required to provide the necessary treatment. A good question to ask yourself and your colleagues requesting PICC insertion is "How many lumens do you need" rather than how many lumens do you want. This is especially relevant in pediatrics where vessel size is so small. A multi-lumen PICC will surely make medication administration easier in complex patients requiring multiple therapies. However, it is these complex patients that are at a higher risk of developing complications such as infection, occlusion, and thrombosis (Raffini et al. 2009). Collaboration with healthcare professionals such as pharmacists will assist in planning medication administration to better utilize single lumen devices and avoid the unnecessary risk of complications related to multiple lumen PICCs. Additionally, the strong association between catheter/vein ratio and PICC-related thrombosis should be considered when choosing an appropriately sized PICC to insert (Sharp et al. 2015). The PICC should occupy no more than $45 \%$ of the selected vessel at its smallest point to ensure there is adequate blood flow through the vessel where the PICC is situated (Gorski et al. 2016). An easy rule of thumb is a 3Fr PICC requires a $3 \mathrm{~mm}$ vessel, 4Fr PICC requires a $4 \mathrm{~mm}$ vessel, and so forth. Prevention, recognition, and early management of thrombosis are increasingly important to ensure vessel health and preservation in these complex pediatric patients who will require lengthy and sometimes lifelong vascular access.

\subsection{Catheter Materials and Design}

Performance and reliability of a PICC is reliant on catheter material that is suitably flexible to reduce vessel irritation and patient discomfort and has adequate flow rates and structural integrity to achieve successful infusion therapy. This combination can be difficult to achieve in catheters that are small enough for pediatric vessels. Traditional silicone catheter material is soft, requiring more plastic in the outer wall to ensure stability of the catheter. As the size of the PICC is determined by the outer diameter of the catheter, a thicker outer wall limits the size of the inner lumen which in turn affects flow rates. This is clinically significant in pediatric catheters $3 \mathrm{Fr}$ and smaller as viscous infusions or high-volume infusions might be more difficult.

An alternative to silicone is polyurethane, a hardier material that does not require the same degree of thickness in its outer walls to provide catheter integrity. Polyurethane is now the material of choice for PICCs, providing a stronger catheter with a larger internal lumen that can provide better flow rates, especially in small pediat- 
ric catheters (Poli et al. 2016). Much variability exists in polyurethane, and Carbothane ${ }^{\mathrm{TM}}$ is a third-generation polyurethane that increases conformability within the vein (May et al. 2015).

Thrombosis and intraluminal occlusions are the most common cause of PICC failure in pediatric patients (Menendez et al. 2016; Morgenthaler and Rodriguez 2016). A recent development in PICC material involves the incorporation of antithrombogenic material $\left(\right.$ Endexo $\left.^{\mathrm{TM}}\right)$ throughout the catheter-the inside, the outside, and the cut surface. Therefore, when PICCs are trimmed to a more suitable length for pediatric patients (Interface Biologics 2017), the risk of thrombotic complications including occlusion is greatly reduced. A recent randomized control trial in pediatric inpatients demonstrated a $50 \%$ reduction in PICC failure when antithrombogenic catheters were used compared to a power injectable polyurethane PICC (Kleidon et al. 2018). Additionally, significantly fewer complications such as occlusion occurred in patients with antithrombogenic PICCs.

PICCs with an antimicrobial coating have been associated with fewer central line-associated bloodstream infections (CLABSI) and should be considered in high-risk patients or when prolonged therapy is anticipated (Kramer et al. 2017). Children requiring insertion of PICCs are often immunocompromised or have comorbidities or an existing infection that increases their risk for developing CLABSI.

Traditionally, PICCs have had a clamp to reduce blood reflux. An alternative to a clamp is a valve positioned either at the distal or proximal PICC end. An inbuilt valve in pediatric PICCs might be preferential to an external clamp that children can play with and potentially undo, allowing blood to reflux into the unclamped catheter and increase the risk of occlusion within the PICC lumen.

\subsection{Tunneling}

Novel insertion techniques are often required in pediatric patients because their infusion needs require a catheter that is greater than their peripheral vessels can accommodate. Additionally, when multiple infusions are required, a multiple lumen cath- eter may be required, necessitating a larger vessel to accommodate this. Non-tunneled central venous catheters are often used in these situations; however, pediatric patients have small necks making care and maintenance of multi-lumen, non-tunneled central venous catheters difficult. Situations that might require novel insertion techniques include:

- Peripheral vessels too small to insert an appropriately sized catheter to complete treatment.

- Axillar or femoral most appropriate peripheral vein.

- Stenosis between axillar and subclavian.

- Renal disease that requires preservation of peripheral veins for future fistula.

In the above situations where a PICC is not able to be inserted in the traditional manner, the actual catheter can be used to instead insert a tunneled PICC. The advantage of this is that the femoral or axillary vein is punctured, but the exit site or point of skin puncture is more distal, midupper arm or mid-thigh (see Fig. 14.9). The advantages to this technique include lower microbial load and increase in comfort and postoperative care and maintenance. A long subcutaneous tunnel is created from the point of skin entry to the point of vein entry in either the femoral or axillary vein (Fig. 14.9) (Ostroff and Moureau 2017). A variation to this is a tunneled non-cuffed

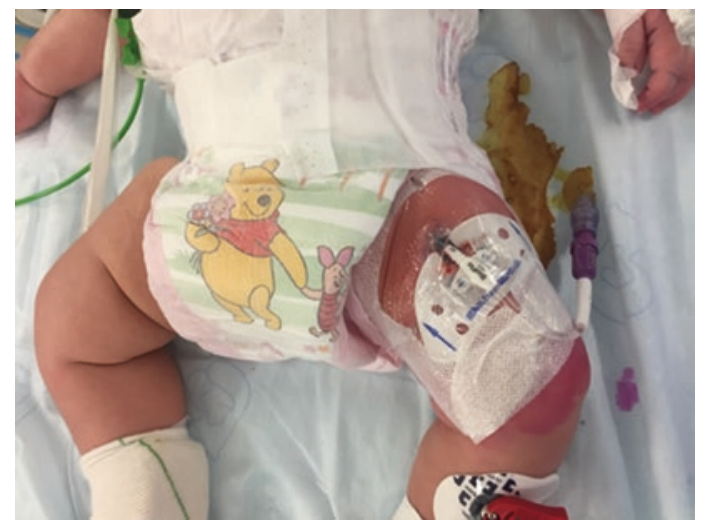

Fig. 14.9 Post-insertion tunneled PICC placement. PICC exists mid-thigh; long subcutaneous tunnel to femoral vein at its largest point to accommodate $3 \mathrm{Fr}$ catheter in $3.2 \mathrm{~kg}$ baby (used with permission T. Kleidon) 
Table 14.3 Centrally inserted central catheters

\begin{tabular}{|c|c|c|c|}
\hline Property & $\begin{array}{l}\text { Non-tunneled central venous } \\
\text { catheter (nt-CVC) }\end{array}$ & $\begin{array}{l}\text { Tunneled cuffed central venous } \\
\text { catheter (Tc-CVC) }\end{array}$ & $\begin{array}{l}\text { Totally implanted venous port } \\
\text { device (TIVPD) }\end{array}$ \\
\hline Size & $\begin{array}{l}\text { 4Fr-8Fr } \\
\text { Single and multiple lumen }\end{array}$ & $\begin{array}{l}\text { 2.7Fr-12.5Fr } \\
\text { Single and multiple lumen }\end{array}$ & $\begin{array}{l}\text { 5Fr-9.6Fr } \\
\text { Single and double lumen }\end{array}$ \\
\hline Length & Variable, $4-12 \mathrm{~cm}$ & Variable, cut to length & Variable, cut to length \\
\hline $\begin{array}{l}\text { Insertion } \\
\text { position }\end{array}$ & Neck or groin & Neck & Neck \\
\hline Tip position & Central & SVC/RA junction & SVC/RA junction \\
\hline $\begin{array}{l}\text { Tip } \\
\text { confirmation }\end{array}$ & $\begin{array}{l}\text { Confirmation of venous } \\
\text { placement }\end{array}$ & CXR & CXR \\
\hline Advantages & $\begin{array}{l}\text { - Short term } \\
\text { - Quick procedure } \\
\text { - Rapid infusion } \\
\text { - Blood sampling } \\
\text { - Hemodynamic monitoring } \\
\text { - Multiple infusions possible }\end{array}$ & $\begin{array}{l}\text { - Long-term device } \\
\text { - (usually } \geq 3 \text { months) } \\
\text { - External device } \\
\text { - No needles required to } \\
\text { access } \\
\text { - Multiple lumens } \\
\text { - Tunnel reduces infection } \\
\text { risk } \\
\text { - Tunnel placement to patient } \\
\text { preference } \\
\text { - Cuff to stabilize catheter } \\
\text { - Long-term, frequent use } \\
\text { (e.g., anticancer treatment) }\end{array}$ & $\begin{array}{l}\text { - Long-term device } \\
\text { - (usually } \geq 3 \text { months) } \\
\text { - Totally implanted } \\
\text { - Reduced risk profile when not } \\
\text { accessed } \\
\text { - Less interference with patient } \\
\text { lifestyle when not accessed } \\
\text { - Tunnel placement to patient } \\
\text { preference } \\
\text { - Long-term, infrequent use } \\
\text { (e.g., cystic fibrosis, } \\
\text { hemophilia) }\end{array}$ \\
\hline Disadvantages & $\begin{array}{l}\text { - Usually placed high on } \\
\text { neck, difficult to manage } \\
\text { - Insertion directly into vessel } \\
\text { increases infection risk }\end{array}$ & $\begin{array}{l}\text { - Complications of long-term } \\
\text { external device } \\
\text { - Fracture } \\
\text { - Dislodgement } \\
\text { - Infection } \\
\text { - Weekly care and } \\
\text { maintenance }\end{array}$ & $\begin{array}{l}\text { - Needle phobia } \\
\text { - Port body erosion } \\
\text { - Weekly needle change when } \\
\text { in use }\end{array}$ \\
\hline
\end{tabular}

central venous catheter, whereby a central vessel such as the internal jugular is punctured, and the PICC is tunneled and exists in the anterior chest wall. It is important to differentiate between the two and avoid simply calling the procedure a tunneled PICC. In a true tunneled PICC, a central vessel, which has an extended complication profile including the risk of pneumothorax, uncontrolled bleeding, etc., is punctured rather than a peripheral vessel.

\subsubsection{Short CVADs}

Despite the difficulties in managing short or nontunneled central venous catheters (CVCs), they have a place in pediatric infusion therapy. They are traditionally placed immediately prior to anesthetic in the pediatric intensive care unit and, in some circumstances, in the emergency depart- ment. The subclavian, jugular, brachiocephalic, or femoral vein is the origin of access, and the catheter tip is ideally placed in a large central vein, enabling safe administration of various drugs including vesicants as well as hemodynamic monitoring and blood sampling. The advantage of these catheters in the pediatric setting is the large caliber, multi-lumen catheter, and the short length, enabling multiple, rapid infusions if necessary (see Table 14.3). Short CVCs or non-tunneled central venous catheters (ntCVCs) are typically used for 1-2 weeks but may remain in situ for longer if necessary and show no signs of complication such as infection.

\subsubsection{Catheter Material}

As with PICCs, various materials have been used to coat and impregnate CVCs to reduce 
the risk of infection and occlusion. As previously mentioned, children need smaller central venous catheters which tend to occlude more readily than larger catheters. Additionally, the most common route of infection is migration of skin organisms at the insertion site into the catheter tract. Newborn infants and low birth weight infants are especially susceptible to infection due to their immature immune system and thin immature skin. Additionally, infants and pediatric patients in the intensive care unit receive multiple medications and require frequent monitoring, necessitating more frequent catheter manipulation, further increasing their risk of infection. To prevent these complications and reduce healthcare costs, various impregnated central venous catheters have been trialed in the pediatric setting. These include heparin-bonded catheters, chlorhexidine and silver sulfadiazine, and minocycline-rifampin. These treatments have shown a reduction in catheter-related bloodstream infection (CR-BSI); however, risks associated with the use of these treatments including resistance to chlorhexidine, previously induced in vitro, chlorhexidine anaphylaxis, and antimicrobial resistance have not been discounted. Therefore, use of coated and impregnated catheters should be reserved for instances where risk of infection is high (Balain et al. 2015; Gilbert et al. 2016; Shah and Shah 2014; Timsit et al. 2011).

\subsubsection{Tunneled and Totally Implanted Devices}

Long-term tunneled central venous catheters are characterized by whether they are an external device such as a tunneled cuffed central venous catheter (tc-CVC) or a totally implanted venous port device (TIVPD). Tunneled catheters that are external have a Dacron cuff to prevent migration of microorganisms along the subcutaneous tract as well as provide an anchor to reduce the risk of dislodgement once the cuff adheres to the subcutaneous tract. TIVPDs have a port body and septum that is implanted on the anterior upper chest wall. A catheter is attached to the port body hub and tunneled through the subcutaneous tract and enters the venous system in the supraclavicular region, usually via the jugular route. The catheter tips of tc-CVC and TIVPD terminate in a central position making them ideal for the long-term administration of all infusions.

Tc-CVCs are single and multi-lumen devices predominantly used in pediatric patients requiring long-term, frequent central venous access, i.e., those patients requiring central venous access for 3 months or longer and receiving anticancer treatment and bone marrow transplant or requiring long-term parenteral nutrition (see Table 14.3). Traditionally these catheters are large bore, capable of providing high-volume infusion and reliable blood sampling, and reduce the need for venipuncture in pediatric patients, which is often a difficult, anxiety-provoking, and time-consuming process. Tc-CVCs have a reduced incidence of infection compared to ntCVCs due to the separation of insertion and exit points of the catheter.

A TIVPD is an ideal device for children and adults who require long-term intermittent central venous access capable of delivering reliable infusions and blood sample, because when it is not in use, it has no external accessories, reducing the risk of complications such as infection, dislodgement, and fracture (Kulkarni et al. 2014). However, this reduced risk is negated when the device is in use. Traditionally, TIVPDs are suitable for patients with cystic fibrosis and hematological conditions requiring infrequent infusion and blood sampling. TIVPD requires access via a special slant cut Huber needle inserted through the skin into the port body septum; therefore, TIVPDs may not be suitable for patients with needle phobia.

\subsection{When to Consider Alternatives}

Children who have had multiple previous vascular access procedures may now have venous occlusion, limiting the use of traditional vascular 
access sites. Occlusion of large central veins can occur when neonates have extended intensive care admissions requiring large vascular access devices to provide the necessary emergent therapy during their intensive care admission. Additionally, children who have required multiple vascular access procedures due to previously failed central venous access may also have limited venous access.

\subsubsection{Nontraditional Routes}

Large collateral veins will eventually develop in the neck when one or both of the internal jugular veins become occluded. Potential collateral veins include the anterior jugular and inferior thyroid veins and the jugular arch, which can often be used for vascular access if an established connection with the brachiocephalic vein and superior vena cava is formed (Lorenz et al. 2001; Shankar et al. 2002; Willetts et al. 2000; Wragg et al. 2014).

The right and left brachiocephalic veins may remain patent in the presence of an ipsilateral jugular and subclavian occlusion. When the ultrasound is placed in the supraclavicular position with caudal tilt, it is easy to identify the brachiocephalic vein in infants and pediatric patients. In situations where the jugular and subclavian veins are small due to prematurity or vessel anomaly, or if a large catheter is required to provide the necessary medical treatment, use of the larger brachiocephalic vein is a better alternative to the smaller jugular and subclavian veins (Badran et al. 2002).

Transhepatic and translumbar catheters have been used in the past to provide a route for vascular access when all veins of the neck and groin have been exhausted. Today, with the use of ultrasound, fewer venous occlusions resulting in venous insufficiency occur, and this route is almost never required. If venous insufficiency occurs, discussion with the interdisciplinary team should include interventional radiology to discuss these extended options (Barnacle 2014).

\subsubsection{Recanalization}

Large veins that have been occluded for some time can often be recanalized with the use of a dilator and guidewire following puncture of a vein peripheral to the occlusion. Recanalization is time-consuming and costly and should only be attempted by experienced personnel such as interventional radiologists (Barnacle et al. 2008; Barnacle 2014).

\subsection{Summary}

Numerous vascular access options exist for pediatric patients, and selecting the right device can be difficult, complicated by the often uncertain prognostic and treatment trajectories. It is important to clarify the clinical needs of the patient and involve all relevant clinicians in the decisionmaking process to ensure the right device is inserted to ensure safe practice and vessel health and preservation.

\section{Case Study}

Tessa is a 10-month-old toddler; her mom has brought her to the emergency department. Tessa presents with fever, a swollen left forearm, and miserable with coryzal symptoms. Although she has been crawling for the past 3 months, she now refuses to weight bear. The provisional diagnosis is osteomyelitis, and you are tasked with inserting a PIVC. Tessa weighs $12 \mathrm{~kg}$, has limited venous access sites to the naked eye, and sucks her right thumb.

1. What are the venous access options that might be suitable for Tessa?

2. What site would you consider for placement?

3. Are you confident in successful PIVC insertion?
(a) What are your options if you are not? 


\section{Case Study}

Max is 6-year-old boy with a compound fractured tibia. Postoperative recovery has been complicated with infected pin sites from his external fixation device. Max is prescribed $250 \mathrm{mg}$ vancomycin three times per day. Max had a PIVC inserted intraoperatively that has now stopped working after receiving his second dose of vancomycin.

1. What are the venous access options that might be suitable for max?

2. As his vascular access specialist, what factors do you need to consider prior to choosing a suitable device?

3. Which interdisciplinary healthcare workers might it be appropriate to discuss Max's options with to help you choose the right vascular access device for max?

\section{Case Study}

Lily is born at 38 weeks gestation, a presumably normal birth and uncomplicated delivery. At 1 day of age, Lily is noted to be pale and lethargic. A blood test reveals anemia and thrombocytopenia. Lily does not have a genetic reason for this abnormality. Initial treatment with packed red blood cells and platelets did not improve Lily's platelet count. Due to uncontrolled thrombocytopenia, her medical team chose a PICC to treat Lily rather than insertion of a centrally inserted central venous catheter. The measurements of Lily's basilic and axillary veins are $1.4 \mathrm{~mm}$ and $2.1 \mathrm{~mm}$, respectively.

1. What are the venous access options that might be suitable for lily?

(a) Is it appropriate to insert a 3Fr PICC in an upper arm vessel?

2. What other options might be available if a 3Fr PICC is not suitable in Lily's upper arm vessels?
3. Lilly's femoral vein is measured $3.0 \mathrm{~mm}$.

(a) Given Lily's thrombocytopenia, is it safe to puncture a femoral vessel?

(b) What are the risks of inserting a catheter in the femoral vein in an infant?

In collaboration with Lily's hematologist, oncologist, intensivist, and vascular access specialist, the decision to insert a PICC via the femoral vein was made. If bleeding occurs, it is easy to apply pressure to the femoral vein. The risk of infection is high in catheters inserted in the nappy area in infants. Lily's vascular access specialist inserted the PICC by beginning the puncture mid-thigh, then creating a long subcutaneous tunnel before puncturing the femoral vein.

\section{Case Study}

Jeffrey is a 5-year-old boy who is about to start school. He was born with short gut secondary to necrotizing enterocolitis and subsequently is reliant on nutrition through his central venous access device. Jeffrey was fed through his tc-CVC. Jeffrey has had several complications related to his tc-CVC including infection, dislodgement, and fracture. Jeffrey presents to the emergency department with a fractured catheter. Jeffrey finds his current tc-CVC limiting on his lifestyle as he would like to play football and swim.

1. What vascular access options are available to Jeffrey?

2. What are the various risk factors to consider with each device?

3. How important is it to consider Jeffrey's lifestyle for his device choice?

4. Consider which interdisciplinary healthcare professionals you could consult regarding the most appropriate device for Jeffrey. 


\section{Case Study}

Grace is a 6-month-old baby recently diagnosed with infant ALL. Grace will require intensive anticancer therapy and possibly a bone marrow transplant. Grace was born at 32 weeks gestation and spent 12 weeks in the neonatal intensive care unit, requiring multiple vascular access devices to support nutritional feeding initially. However, several line occlusions and fractures resulted in sepsis and extended inpatient stay. Grace ultimately required insertion of a femoral vein catheter due to multiple neck vein occlusions of the subclavian and jugular veins.

1. Are there any potential complicating factors to Grace's vasculature?

2. What vascular access options are available to grace?

3. What size line and how many lumens is grace likely to need to complete her anticancer therapy?

4. Consider which interdisciplinary healthcare professionals you could consult to determine the most appropriate type of device and placement of device.

\section{Summary of Key Points}

1. Pediatric patients have small veins, and this must be considered when determining the most appropriate vascular access plan to successfully complete treatment.

2. Some pediatric treatments will necessitate a larger device; novel insertion techniques should be considered to facilitate treatment with the least risk of complication.

3. There are a variety of devices available to the vascular access clinicians, and choice is not always obvious; however, interdisciplinary consultation will ensure all treatments and vascular access requirements are considered.
4. Tip positioning is important to reduce the risk of device complication and failure.

5. Multi-lumen devices are associated with increased complications and should only be inserted when absolutely necessary.

6. Patient lifestyle and device preference should be considered when possible.

7. Some patients require lifelong vascular access; therefore, every attempt to insert the right device and reduce potential complications to ensure vessel health and preservation should be considered.

\section{References}

Alexandrou E, Ray-Barruel G, Carr PJ, Frost S, Inwood $\mathrm{S}$, Higgins $\mathrm{N}$, et al. International prevalence of the use of peripheral intravenous catheters. J Hosp Med. 2015;10(8):530-3. https://doi.org/10.1002/jhm.2389.

Badran DH, Abder-Rahman H, Abu Ghaida J. Brachiocephalic veins: an overlooked approach for central venous catheterization. Clin Anat. 2002;15(5):345-50. https://doi.org/10.1002/ca.10046.

Balain M, Oddie SJ, McGuire W. Antimicrobialimpregnated central venous catheters for prevention of catheter-related bloodstream infection in newborn infants. Cochrane Database Syst Rev. 2015;(9):Cd011078. https://doi. org/10.1002/14651858.CD011078.pub2.

Barnacle AM. Interventional radiology in infancy. Early Hum Dev. 2014;90(11):787-90. https://doi. org/10.1016/j.earlhumdev.2014.08.017.

Barnacle A, Arthurs OJ, Roebuck D, Hiorns MP. Malfunctioning central venous catheters in children: a diagnostic approach. Pediatr Radiol. 2008;38(4):363-78 . quiz 486-367. https://doi. org/10.1007/s00247-007-0610-2.

Benkhadra M, Collignon M, Fournel I, Oeuvrard C, Rollin $\mathrm{P}$, Perrin M, et al. Ultrasound guidance allows faster peripheral IV cannulation in children under 3 years of age with difficult venous access: a prospective randomized study. Paediatr Anaesth. 2012;22(5):449-54. https://doi.org/10.1111/j.1460-9592.2012.03830.x.

Caparas JV, Hu JP. Safe administration of vancomycin through a novel midline catheter: a randomized, prospective clinical trial. J Vasc Access. 2014;15(4):2516. https://doi.org/10.5301/jva.5000220. 
Children's Health Services. IVAD procedure-intravascular access device, management of (peripheral and central venous access devices). Brisbane: Queensland Government; 2016.

Chopra V, Flanders S, Saint S, Woller S, O'Grady N, Safdar N, et al. The Michigan appropriateness guide for intravenous catheters (MAGIC): results from a multispecialty panel using the RAND/UCLA appropriateness method. Ann Intern Med. 2015;163(6 Suppl):S1-40. https://doi.org/10.7326/M15-0744.

Gilbert RE, Mok Q, Dwan K, Harron K, Moitt T, Millar $\mathrm{M}$, et al. Impregnated central venous catheters for prevention of bloodstream infection in children (the CATCH trial): a randomised controlled trial. Lancet. 2016;387(10029):1732-42. https://doi.org/10.1016/ s0140-6736(16)00340-8.

Gorski LA, Hagle ME, Bierman S. Intermittently delivered IV medication and $\mathrm{pH}$ : reevaluating the evidence. J Infus Nurs. 2015;38(1):27-46. https://doi. org/10.1097/nan.0000000000000081.

Gorski L, Hadaway L, Hagle M, McGoldrick M, Orr M, Doellman D. Infusion therapy: standards of practice (supplement 1). J Infus Nurs. 2016;39(1S):S1-S159.

Hatakeyama N, Hori T, Yamamoto M, Mizue N, Inazawa $\mathrm{N}$, Igarashi K, et al. An evaluation of peripherally inserted central venous catheters for children with cancer requiring long-term venous access. Int $\mathrm{J}$ Hematol. 2011;94(4):372-7. https://doi.org/10.1007/ s12185-011-0928-2.

Interface Biologics. Surface modification technology platform; 2017. http://www.interfacebiologics.com/ endexo.htm.

Juric S, Zalik B. An innovative approach to near-infrared spectroscopy using a standard mobile device and its clinical application in the real-time visualization of peripheral veins. BMC Med Inform Decis Mak. 2014;14:100. https://doi.org/10.1186/ s12911-014-0100-z.

Kleidon TM, Ullman AJ, Zhang L, et al. How does your PICCOMPARE? A pilot randomized controlled trial comparing Various PICC materials in pediatrics. J Hosp Med. 2018. E1-e9

Kleidon TM, Cattanach P, Mihala G, Ullman AJ. Implementation of a paediatric peripheral intravenous catheter care bundle: a quality improvement initiative. J Paediatr Child Health. 2019.

Kramer RD, Rogers MA, Conte M, Mann J, Saint S, Chopra V. Are antimicrobial peripherally inserted central catheters associated with reduction in central line-associated bloodstream infection? A systematic review and meta-analysis. Am J Infect Control. 2017;45(2):108-14. https://doi.org/10.1016/j. ajic.2016.07.021.

Kulkarni S, Wu O, Kasthuri R, Moss JG. Centrally inserted external catheters and totally implantable ports for the delivery of chemotherapy: a systematic review and meta-analysis of device-related complications. Cardiovasc Intervent Radiol. 2014;37(4):9901008. https://doi.org/10.1007/s00270-013-0771-3.
L'Acqua C, Hod E. New perspectives on the thrombotic complications of haemolysis. Br J Haematol. 2015;168(2):175-85. https://doi.org/10.1111/ bjh. 13183.

Lorenz JM, Funaki B, Van Ha T, Leef JA. Radiologic placement of implantable chest ports in pediatric patients. Am J Roentgenol. 2001;176(4):991-4. https://doi.org/10.2214/ajr.176.4.1760991.

Malyon L, Ullman AJ, Phillips N, Young J, Kleidon T, Murfield J, Rickard CM. Peripheral intravenous catheter duration and failure in paediatric acute care: a prospective cohort study. Emerg Med Australas. 2014;26(6):602-8. https://doi. org/10.1111/1742-6723.12305.

Marsh N, Webster J, Mihala G, Rickard C. Devices and dressings to secure peripheral venous catheters to prevent complications. Cochrane Database Syst Rev. 2015;(6):CD011070. https://doi. org/10.1002/14651858.CD011070.pub2.

May RM, Magin CM, Mann EE, Drinker MC, Fraser JC, Siedlecki CA, et al. An engineered micropattern to reduce bacterial colonization, platelet adhesion and fibrin sheath formation for improved biocompatibility of central venous catheters. Clin Transl Med. 2015;4:9. https://doi.org/10.1186/s40169-015-0050-9.

Menendez JJ, Verdu C, Calderon B, Gomez-Zamora A, Schuffelmann C, de la Cruz JJ, de la Oliva P. Incidence and risk factors of superficial and deep vein thrombosis associated with peripherally inserted central catheters in children. J Thromb Haemost. 2016;14(11):215868. https://doi.org/10.1111/jth.13478.

Morgenthaler TI, Rodriguez V. Preventing acute careassociated venous thromboembolism in adult and pediatric patients across a large healthcare system. J Hosp Med. 2016;11(Suppl 2):S15-s21. https://doi. org/10.1002/jhm.2662.

Ostroff M, Moureau N. Report of modification for peripherally inserted central catheter placement: subcutaneous needle tunnel for high upper arm placement. J Infus Nurs. 2017;40(4):232-7. https://doi. org/10.1097/nan.0000000000000228.

Pandurangadu AV, Tucker J, Brackney AR, Bahl A. Ultrasound-guided intravenous catheter survival impacted by amount of catheter residing in the vein. Emerg Med J. 2018;35(9):550-5.

Poli P, Scocca A, Di Puccio F, Gallone G, Angelini L, Calabro EM. A comparative study on the mechanical behavior of polyurethane PICCs. J Vasc Access. 2016;17(2):175-81. https://doi.org/10.5301/ jva.5000452.

Raffini L, Huang YS, Witmer C, Feudtner C. Dramatic increase in venous thromboembolism in children's hospitals in the United States from 2001 to 2007. Pediatrics. 2009;124(4):1001-8. https://doi. org/10.1542/peds.2009-0768.

Rickard C, Webster J, Wallis M, Marsh N, McGrail M, French V, et al. Routine versus clinically indicated replacement of peripheral intravenous catheters: a randomised controlled equivalence trial. Lancet. 2012;380(9847):1066-74. 
Royal College of Nursing. Standards for infusion therapy. London, United Kingdom; 2016.

Shah PS, Shah N. Heparin-bonded catheters for prolonging the patency of central venous catheters in children. Cochrane Database Syst Rev. 2014;(2):Cd005983. https://doi.org/10.1002/14651858.CD005983.pub3.

Shankar KR, Abernethy LJ, Das KS, Roche CJ, Pizer BL, Lloyd DA, Losty PD. Magnetic resonance venography in assessing venous patency after multiple venous catheters. J Pediatr Surg. 2002;37(2):175-9.

Sharp R, Cummings M, Fielder A, Mikocka-Walus A, Grech C, Esterman A. The catheter to vein ratio and rates of symptomatic venous thromboembolism in patients with a peripherally inserted central catheter (PICC): a prospective cohort study. Int J Nurs Stud. 2015;52(3):677-85. https://doi.org/10.1016/j. ijnurstu.2014.12.002.

Tagalakis V, Kahn SR, Libman M, Blostein M. The epidemiology of peripheral vein infusion thrombophlebitis: a critical review. Am J Med. 2002;113(2):146-51.

Timsit J-F, Dubois Y, Minet C, Bonadona A, Lugosi $\mathrm{M}$, Ara-Somohano $\mathrm{C}$, et al. New materials and devices for preventing catheter-related infections. Ann Intensive Care. 2011;1(1):34. https://doi. org/10.1186/2110-5820-1-34.

Ullman AJ, Cooke M, Kleidon T, Rickard CM. Road map for improvement: point prevalence audit and survey of central venous access devices in paediatric acute care. J Paediatr Child Health. 2016; https://doi.org/10.1111/ jpc. 13347.

Webster J, Osborne S, Rickard CM, New K. Clinicallyindicated replacement versus routine replacement of peripheral venous catheters. Cochrane Database Syst Rev. 2015;8:CD007798. https://doi. org/10.1002/14651858.CD007798.pub4.

Westergaard B, Classen V, Walther-Larsen S. Peripherally inserted central catheters in infants and childrenindications, techniques, complications and clinical recommendations. Acta Anaesthesiol Scand. 2013;57(3):278-87. https://doi.org/10.1111/ aas. 12024 .

Willetts IE, Ayodeji M, Ramsden WH, Squire R. Venous patency after open central-venous cannulation. Pediatr Surg Int. 2000;16(5-6):411-3.

Wragg RC, Blundell S, Bader M, Sharif B, Bennett J, Jester I, et al. Patency of neck veins following ultrasound-guided percutaneous Hickman line insertion. Pediatr Surg Int. 2014;30(3):301-4. https://doi. org/10.1007/s00383-013-3416-3.

Zempsky WT. Optimizing the management of peripheral venous access pain in children: evidence, impact, and implementation. Pediatrics. 2008;122(Suppl 3):S1214. https://doi.org/10.1542/peds.2008-1055c.

Open Access This chapter is licensed under the terms of the Creative Commons Attribution 4.0 International License (http://creativecommons.org/licenses/by/4.0/), which permits use, sharing, adaptation, distribution and reproduction in any medium or format, as long as you give appropriate credit to the original author(s) and the source, provide a link to the Creative Commons license and indicate if changes were made.

The images or other third party material in this chapter are included in the chapter's Creative Commons license, unless indicated otherwise in a credit line to the material. If material is not included in the chapter's Creative Commons license and your intended use is not permitted by statutory regulation or exceeds the permitted use, you will need to obtain permission directly from the copyright holder. 